\title{
THE AMENDMENT OF THE BIRTHS AND DEATHS REGISTRATION ACT.*
}

\author{
By EDMUND M. SMITH, M.D. Edin.; D.P.H. Camb.; \\ Medical Officer of Health, City of York; \\ President of the Yorkshire Branch.
}

$\mathrm{T}$ is evident that we shall have to be persistent in order to obtain
the long and much-desired amendment of this Act. A Select Committee of the House of Commons considered and reported upon the subject so long ago as 1893, and the Physical Deterioration Committee made important recommendations in 1904. And yet nothing has been done.

I need not dilate upon the need for amendment. Fairly exhaustive papers upon the subject by Dr. Kaye, Dr. Snell of Coventry, and Dr. Walford of Cardiff, have recently appeared in our Journal, Public Health.

I will, therefore, only summarize a few of the chief suggestions in order to propose a resolution.

The following were some of the more important conclusions of the Select Committee of the House of Commons on the subject in 1893 :-

1. That in no case should a death be registered unless on certificate of a registered medical practitioner or of the coroner after inquest.

2. That in each sanitary district a public medical certifier should be appointed to investigate all deaths uncertified.

3. That the fact of death should be verified by the medical attendant, but if that be impracticable, on the ground of distance or other sufficient reason, then a certificate should be signed by two persons verifying the death.

4. That medical practitioners should be required to send certificates of the cause of death direct to the Registrar.

5 . That a compulsory form of certificate should be prescribed.

6. That still-births which have reached the stage of development of seven months should require registration upon the certificate of a registered medical practitioner.

7. That burial should take place only on the certificate of a registrar.

The Inter-departmental Committee on Physical Deterioration were emphatically of opinion that still-births should be registered,-

* Read before the meeting of the Yorkshire Branch at Huddersfield, December 14th, 1906, and discussed at the meeting at Doncaster, April 19th, 1907. 
"As, apart from the advantages a system of registration would have in making it easier to bring home instances of malpractice, a knowledge of the facts as to the frequency of still-births would be of great value towards elucidating the causes of infant mortality, by throwing light on the antenatal conditions prejudicial to the survival of the fotus.

"By the system under which deaths are registered, a medical certificate as to the cause of death is not absolutely essential to the registration of a death, or the burial of a dead body, although the certificate is always asked for by the Registrar. Having regard to the heavy mortality affecting children of tender years, the Committee were of opinion that the death of no child should be registered in the absence of a medical certificate as to the cause of death. Every witness who touched the subject was strongly in favour of this amendment of the law as the best means of bringing home to the careless parent the consequences of culpable neglect."

The Committee, therefore, recommended that "still-births should be registered," and that:-

"A medical certificate as to the cause of death should invariably be required before the death of any child, or, indeed, of any other person, is registered. Moreover, the medical certificate should be regarded as confidential, and its contents should never be divulged by the Registrar, as is permissible at present, to the friends of the deceased. It should be sent by the local Registrar direct to the Registrar-General."

These opinions have been strongly emphasized by the Infantile Mortality Conference of last June.

The chief stated causes of "uncertified" deaths are as follows: premature birth, congenital defects, convulsions and dentition, atrophy and debility, diarrhoeal diseases, tubercular diseases, measles, apoplexy, heart diseases and other diseases of the circulatory system, bronchitis, pneumonia, and old age.

Happily, the percentage of deaths "uncertified" has been declining for some years past (e.g., from 4.85 per cent in 1878 to 1.62 in 1904). But the proportion of such deaths under the age of twelve months still remains unsatisfactorily high, as the following statement indicates :-

UNCERTIFIED DEATHS UNDER ONE YEAR OF AGE.

\begin{tabular}{c|c|c|c|c} 
Year. & Total. & $\begin{array}{c}\text { Percentage of total } \\
\text { "uncertified" } \\
\text { at all ages. }\end{array}$ & $\begin{array}{c}\text { Percentage of above } \\
\text { under age of three } \\
\text { months. }\end{array}$ & $\begin{array}{c}\text { Percentage of latter } \\
\text { not referred to } \\
\text { Coroner. }\end{array}$ \\
\hline 1898 & 4940 & 47 & 68 & 40 \\
1904 & 3736 & 42 & 68 & 40 \\
\hline
\end{tabular}

In 1898 the Registrar-General said, in his Annual Report, that " the 2,500 deaths which had neither been certified nor referred to coroners included the following :-- 
(a) Cases attended by qualified though unregistered medical practitioners ; (b) Cases informally attested ;* (c) Cases attended by midwives; and $(d)$ Cases that had received no skilled attendance in their last illness."

There is abundant demand, then, for the amendment of the present system of the registration of both births and deaths, and upon this matter we ought not to let the Government rest until amendment has been achieved.

I venture briefly to state the chief suggestions which have been made regarding the amendments required:

1. In order to carry out the education of mothers as early as necessary, and in order to secure the maximum of breast feeding, we require to have much earlier notification or registration of births. We congratulate our colleague, Dr. Moore, and the Mayor and town of Huddersfield, upon having obtained Parliamentary powers for securing the notification of every birth within forty-eight hours. But, notwithstanding all that has been said to the contrary, I fail to see why we should not be able to have the legal registration of births within at most three days. The present limit of forty-two days is absurdly extended. Surely it would be as easy for the father (or some person present at birth) to register immediately after birth, and registration would then be much less likely to be forgotten or overlooked. If the father requires half a day's absence from work in order to do it, then he should take it; he frequently takes half a day "off" for much less important business.

2. There is no necessity here to re-state the several undeniable arguments in favour of the compulsory registration of all still-births. They should be registered both as births and as deaths, otherwise statistical difficulties would ensue. They are registered as one or both in nearly every other civilized country but ours, and the necessity for their registration in this country has become seriously intensified by the Midwives Act of 1902 .

3. But this amendment would be covered by another one, even more important and satisfactory, viz.: No body of a child which was born, living or dead, after the seventh month of pregnancy, should be buried without the duly registered certificate of a qualified medical practitioner, or of a coroner. Further, there should be no such thing as what are termed to-day " uncertified deaths." All cases of death

* "In some of these cases an informal statement of the probable cause of death was made by a registered medical practitioner, who had either attended the deceased in a previous illness, or had been called in only when the patient was moribund. In other cases the practitioner in attendance was unqualified." 
medically uncertified should, under compulsion, be referred by the local Registrar to the Coroner, who should order a post-mortem and hold an inquest, if not in every case, at least in those in which there is the slightest room for doubt. This would do much to put a stop to the neglect of sick children and of aged relatives, to carelessness during pregnancy, to the deliberate permission of the death of illegitimates and other "undesirable" children, and to that new form of insanity called "Christian science"; for there is a most wholesome dread of coroners' inquests amongst the mass of the people.

4. All certificates of the cause of death, required by law to be sent to the Registrar, should be delivered or posted to him by the certifying medical practitioner, direct, and under sealed cover. There is much reason to believe that the present method of delivery to the informant or relatives seriously vitiates the correctness of certification, and, consequently, we obtain no correct statistics of deaths due to such causes as alcoholism or venereal disease.

5. The certifying medical practitioner should be paid a fee by the National Exchequer for each certificate of the cause of death required to be sent by him to the Registrar, only one fee being paid in respect of each death; the certificate to state that he had seen the body after death, and to give the canse of death fully, and as truthfully as possible, according to clear directions stated on the form of certificate; there should be only one legal form of certificate, the use of which by practitioners should be compulsory. Incomplete or apparently inaccurate certificates should be returned to the certifier by the Registrar-General (through the Superintendent Registrar) for correction.

6. If the District Registrars of deaths be not medical men, at any rate the Superintendent Registrar of Births and Deaths should be a qualified medical man, and it should be his duty to forward the weekly and quarterly returns of the district statistics to the Registrar-General. I am loath to suggest the addition of any more duties to those of the Medical Officer of Health, but I think there would be decided advantage in his being the Superintendent Registrar (with special stipend of course), for then the deaths returned to the Registrar-General would be more properly, and could be more fully classified, and there would be more accurate handling of the deaths of residents and non-residents. Then we could surely arrange for a much more complete interchange of the facts concerning the latter, between one district and another, than at present exists.

In conclusion, I beg to propose that we should recommend the Central Society to urge the Government to promote early legislation 
embodying the following amendments (as amended after Discussion), viz :-

1. The compulsory registration of births within three days after birth.

2. The compulsory registration of still-births.

3. That there should be no registration or burial without a certificate stating the cause of death, from either a qualified medical practitioner, or a coroner, after inquest.

4. That a compulsory form of death certificate be prescribed, that death be verified before certification, that the medical certificate of cause of death be sent direct to the Registrar, under cover, and that such certificate should be paid for out of national funds.

5. That the Certificate for burial given by the Registrars of Deaths be retained by the official of the cemetery and returned to the Registrars of Deaths after the interment.

6. That the Local Government Board's definition of "Residents" and "Non-Residents" be extended so as to comprise the deaths of all persons dying or found dead in a district in which they were not permanently resident: e.g. (a) Visitors to watering places, etc.; (b) Bodies washed ashore from shipwreck or from boat accidents; (c) Sudden deaths in railway stations or carriages, etc., in addition to those occurring in public institutions, or in institutions for the reception of paupers or the mentally or bodily sick.

Salaries of Lady Assistant Medical Officer of Healith.-Miss M. H. Williams, M.B., writes to the British Medical Journal to protest against the salary of $\$ 105$ per annum, which it is proposed to give for wholetime lady assistant medical officers of health in a provincial town. In her opinion, "for qualified medical practitioners to accept this salary is to admit that, from a financial point of view, their whole expenditure on edncation was wasted; and from another point of view is to encourage the rankest sweating, and to further reduce the remuneration in a profession that is already underpaid." The proposed salary is about equal to that paid to lady health visitors in many districts. It is about half or a third of what is paid in West End drapers' shops to the female heads of departments in the ladies' showrooms.

Novel SLAughter-House BY-LAws.-REcent by-laws for slaughterhouses adopted by the Stockport Town Council include the following very useful powers:-

1. It is forbidden to keep animals in any pound, pen, or lair, unless the following space is provided: for each ox, 24 square feet; for each calf, 8 square feet; and for each sheep, lamb, or pig, 6 square feet of floor space.

2. No animal is allowed to be slaughtered until it has first been effectually stunned; as this includes pigs, it may be assumed that the argument that the money-value of pigs' heads is seriously reduced by stumning, has little if any foundation in fact. Much of the public vuisance from pig-slaughtering will be removed by such preliminary stunning.

3. It is forbidden to slaughter any animal in the view of another animal. 